\title{
Line and HR Managers' Perceptions of HR Importance, Effectiveness and Contribution
}

\author{
M. Srimannarayana ${ }^{1}$ \\ ${ }^{1}$ XLRI, Jamshedpur, India \\ Correspondence: M. Srimannarayana, XLRI, Jamshedpur, India. E-mail: sriman@xlri.ac.in
}

Received: September 6, 2015

Accepted: October 21, $2015 \quad$ Online Published: November 25, 2015

doi:10.5539/ijbm.v10n12p249

URL: http://dx.doi.org/10.5539/ijbm.v10n12p249

\begin{abstract}
The present study aimed at assessing line and HR managers' perceptions on importance, effectiveness of HR service delivery areas, HR roles and HR contribution. The data collected from 642 line managers and 194 HR managers working in different organizations in India, formed the basis for the study. The study found that HR professionals perceived higher importance, effectiveness and contributions of HR than line managers. However, both line and HR professionals recognized the importance of HR and its roles for the firm's competitive advantage. It was observed that the effectiveness of HR in the most important areas and roles was higher, while in least important areas it was lower. This study further found that HR policies and procedures created by the HR department and their well-integrated coordination were the major contributions of HR. The study also made an attempt to find an association between HR importance, effectiveness, and contribution and nature of business, geographical orientation of the business and organizational size.
\end{abstract}

Keywords: HR contribution, HR effectiveness, HR importance, line managers

\section{Introduction}

The importance of Human Resource Management (HRM) is significantly increasing in various regions of the world. There is pressure on HR function to measure its effectiveness in the increasingly competitive environment. Historically, a variety of HR measurement methods were used to demonstrate the effectiveness of HR function. One of the methods is surveying its customers. This paper makes an attempt to find the importance, effectiveness and contribution of HR using the survey method. First, it identifies different methods suggested in the HR literature followed by methodology of the study. The respondents' background and results are presented in the subsequent parts of the study.

\section{Review of Literature and Research}

Flamholtz (1985) proposed human resource accounting system to measure HR contribution. Tsui (1987) suggested a multiple constituency approach to evaluate the effectiveness of HR department. Kaplan and Norton (1996) developed Balanced Scorecard (BSC), a measurement framework that helps management to translate strategic goals into operational objectives. Ulrich (1997) showed how HR practices relate to BSC through productivity, people and process indicators. Building upon BSC, Yeung and Berman (1997) identified three paths through which HR practices contribute to business performance. Phillips (1999) identified 12 approaches that have been used to evaluate the HR function such as survey approach, HR reputation approach, HR accounting, HR auditing, HR case studies, HR cost monitoring, competitive benchmarking, key indicators, HR effectiveness index, HR management by objectives, HR profit centers, and return on investment. Fitz-Enz $(2000,2010)$ proposed a return on investment methodology and HR Analytics for measuring HR. Becker, Huselid and Ulrich (2001) outlined HR Scorecard model, which aims at managing HR as a strategic partner, and demonstrating HR's contribution to the financial success. Cascio and Boudreau (2008) proposed a methodology of behavioral costing to measure the financial impact of HR activities, which measures the economic consequences of employees' behavior such as absenteeism, turnover, employee attitudes, work-life programs and employee training. Having reviewed various ways of assessing HR effectiveness, Wright, McMahan, Snell, and Gerhart (2001) classified them into four categories, such as the methods which show empirical evidence of the firm performance linking human resource practices, the methods which demonstrate the value of HR through theoretical modeling, the methods which use actual HR metrics and predicting the monetary value of future human resource investment through analytics, and finally the methods which assess HR effectiveness through surveying its customers. They conducted a survey on $44 \mathrm{HR}$ and 
59 line executives in United States of America on HR effectiveness. The survey found that HR executives consistently rated the HR function's effectiveness higher than did line executives. The greatest differences were observed in this survey on the more important and/or strategic aspects of HR. Mitsuhashi, Park, Wright and Chua (2000) conducted a similar survey in the People's Republic of China. But it did not find any significant differences between line and HR executives' perceptions of importance of each functional area in HRM. However, there were significant differences between line and HR executives' perceptions of the effectiveness of these areas.

\subsection{The Present Study}

Replicating the studies conducted in USA and China, the present study made an attempt to find out the perceptions of line managers on the importance of HR service delivery, HR roles, HR effectiveness and HR contribution. It also aimed at comparing HR and non-HR managers' perception on HR. An attempt is also made to find out an association between their perception and geographical orientation of their companies, nature of business carried out by them, and size of the organizations.

The instrument created by Wright et al. (2001) was used to assess HR services delivery areas. There are 15 items relating to HR service delivery in this instrument as shown in Appendix A. As far as roles are concerned, the framework advocated by Ulrich and Brockbank (2005) was considered, which identified five HR roles such as employee advocate, human capital developer, functional expert, strategic partner and HR leader.

The respondents were asked to answer each of these items on two different scales. First, they were to indicate the relative importance of each of HR service delivery and HR roles items in gaining/maintaining the organization's competitive position on a seven-point scale, with 1 being 'unimportant' and 7 being 'very important'. Second, the respondents were asked to rate current performance of HR department on the same HR service delivery items and roles on a 7 point scale with 1 being 'ineffective' and 7 being 'very effective'.

HR contributions scale consisted of 10 statements (Wright et al., 2001) as shown in Appendix B. The respondents were asked to rate these statements using a 1(Not at all) to 7 (to a great extent).The latter part of the questionnaire consisted of questions relating to demographic information of the respondents. Considering the stratified random sampling method, the questionnaire was administered on 2,900 managers working in different companies located in India during the years 2011 and 2012. 836 filled in questionnaires (194 from HR managers and 642 from line managers) were considered for the analysis. Cronbach's Alpha test was conducted for all items of the questionnaire to examine the reliability of the data collected. Overall reliability value is 0.975 (Cronbach's alpha value). Thus it is found that the data collected was reliable. Item-wise analysis is carried out using mean scores and standard deviations for all items covering HR importance rating, effectiveness rating and HR contribution. Relevant tests of Correlation, Covariance and ANOVA are used to find out differences in the perceptions of the respondents.

\section{The Respondents' Background}

Table 1 presents the background information of the respondents. Based on the nature of business, $61.36 \%$ of respondents represented manufacturing organizations (e.g., Automobile, electrical, electronics, fast moving consumer products, oil and gas, pharmaceuticals, power and steel); $10.41 \%$ of them worked in service organizations (e.g., banking, consulting, financial services, health care, hospitality, and retail services); $28.23 \%$ of them belonged to information technology (IT) and IT enabled services (ITES). As far as the geographical orientation of their organizations is concerned, $44.50 \%$ of them worked in foreign multinational companies; $41.15 \%$ of them represented Indian multinational units; and the remaining of them belonged to local Indian companies. Organizational size-wise, a single largest group of respondents worked in large organizations (34.93\%), which employed more than 10000 employees. The others were distributed to different organizations which employed less than 500 (19.98\%); less than 5000 (23.33\%); and less than 10000 (21.77\%). Functional area-wise, Non-HR respondents constituted more than three-fourths $(76.79 \%)$ of the sample and the remaining were HR professionals. 
Table 1. The respondents' background

\begin{tabular}{lll}
\hline Nature of Business & Sample & Percentage \\
\hline Manufacturing & 513 & 61.36 \\
Service & 87 & 10.41 \\
IT/ITES & 236 & 28.23 \\
Geographic Orientation & & \\
Local Indian companies & 120 & 14.35 \\
Indian multinational companies & 344 & 41.15 \\
Foreign multinational companies & 372 & 44.50 \\
Organizational Size & & \\
Less than 500 & 167 & 19.98 \\
Less than 5000 & 195 & 23.33 \\
Less than 10000 & 182 & 21.77 \\
10000 and above & 292 & 34.93 \\
Functional Area & & \\
HR & 194 & 23.21 \\
Non HR & 642 & 76.79 \\
\hline
\end{tabular}

\section{Results}

Importance of HR Service Delivery Areas: As presented in Figure 1, the HR managers rated the HR service delivery areas to be more important than did the line managers. Major differences of opinion were observed on 'developing HR initiatives that contribute to achieving current and future business goal', where the line managers perceived it to be significantly less important than did the HR managers. However, with the average difference of opinion being 0.36 on a 7 point scale, it seems both the HR and the line managers agreed on the overall importance of HR service delivery areas. Moreover, the correlation for the mean ratings across the two groups was a very strong 0.874 supporting the conclusion of a convergence in opinions, at least in relative terms. Most important areas, as perceived by both the groups, were providing equitable compensation and performance-based incentives, while least important were providing proactive labor relations and controlling benefits cost.

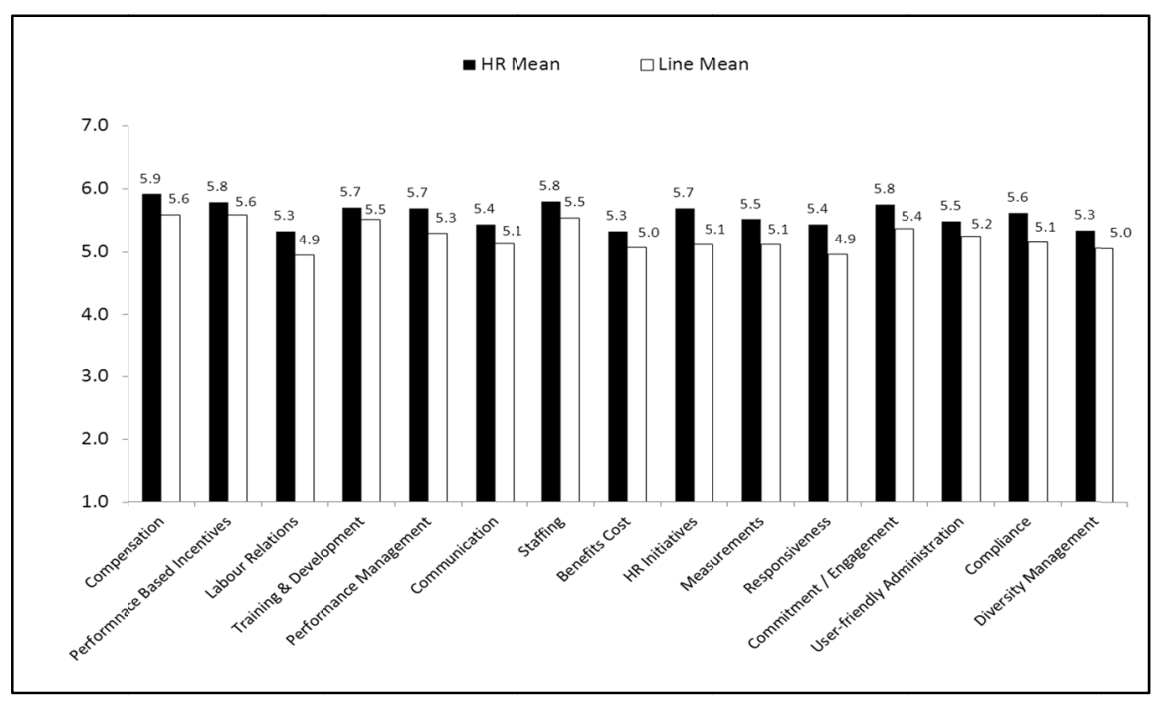

Figure 1. Importance of HR

Importance of HR Roles: It could be seen from Figure 2, that the HR managers rated all five roles - namely employee advocate, human capital builder, functional expert, strategic partner, and HR leader - at almost the same importance level. On the other hand, the line managers had a more differentiating opinion with some roles considered slightly less important than others. The HR Managers rated all roles to be more important as compared to the ratings given by the line managers. Overall, it was found that the role of human capital builder 
was perceived as the most important role, whereas strategic partner role was the least important role of HR professionals.

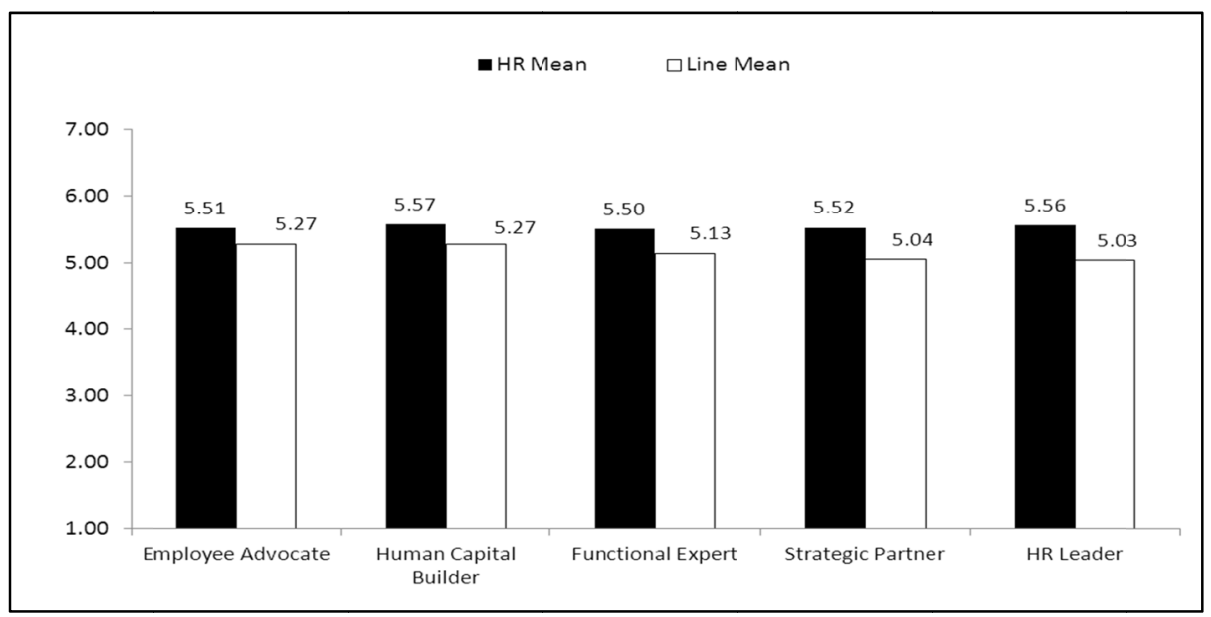

Figure 2. Importance of HR roles

HR Effectiveness: It is evident from Figure 3 that, the HR managers rated the effectiveness of HR service delivery areas higher than did the line managers. With the average difference of opinion being 0.64 on a 7 point scale, it seems the difference in perception of the overall effectiveness of HR service delivery areas between line and HR managers was significant. However, the correlation for the mean ratings across the two groups was strong a 0.763 indicating that line and HR managers agree on the relative effectiveness of HR service delivery areas, while the HR managers over-rated or line managers under-rated (or both) the effectiveness in absolute terms. Considering the opinion of both the groups, the highest effectiveness areas were training and development and equitable compensation. The least ones were providing proactive labor relations support and developing HR initiatives to respond to potential problems. It is significant to note that HR was relatively effective in the most important areas of HR service delivery, and least effective in the least important areas.

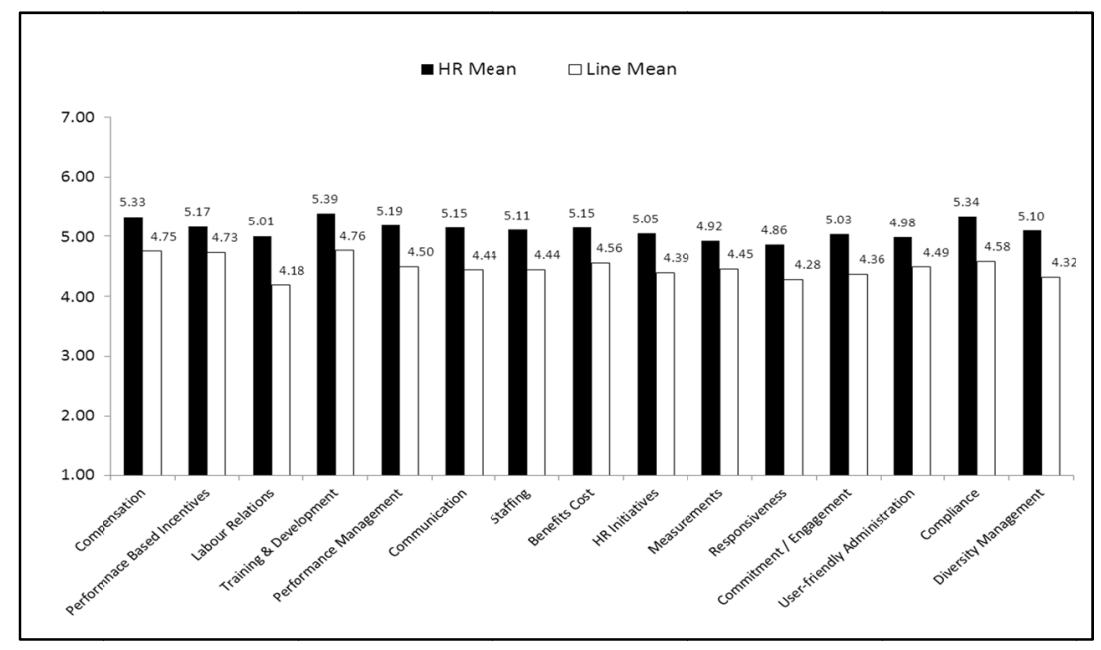

Figure 3. Effectiveness of HR

Effectiveness of HR Roles: When it comes to the effectiveness of HR roles, as usual, the HR managers rated all roles higher than did the line managers (Figure 4). Interestingly, both of them gave top ranking to the role of human capital developer. However, as far as least effective role is concerned, the HR managers rated HR leader role, whereas the line managers considered strategic partner role as least effective. When compared to the 
importance score of HR roles, it is significant to note that the human capital builder, which received the overall highest score in importance, received overall highest score in effectiveness too.

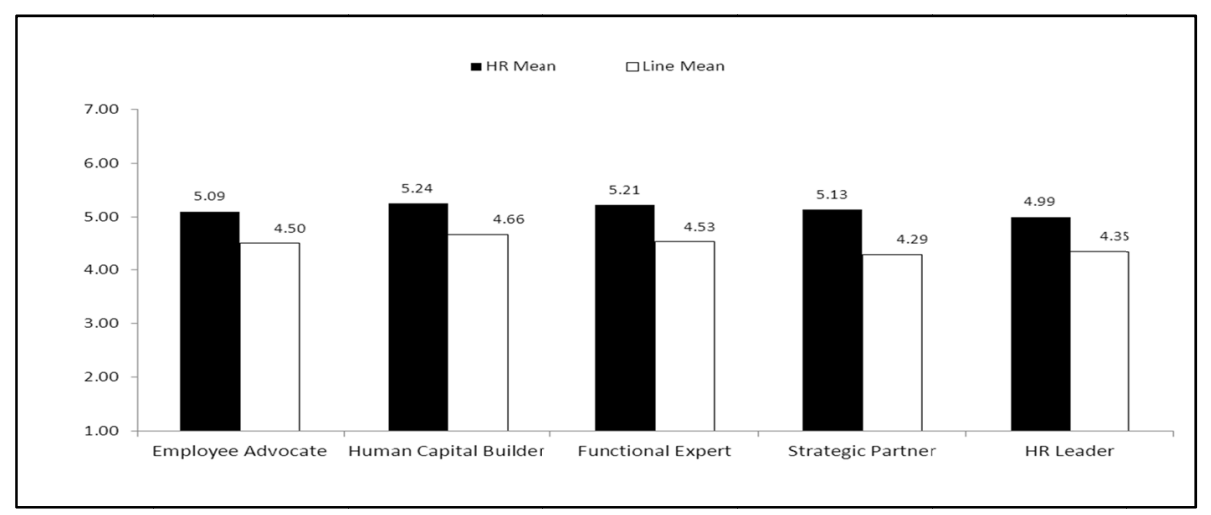

Figure 4. Effectiveness of HR roles

Considering that, in general, HR's effectiveness in the most important areas and roles was higher, while in least important areas it was lower, it seems that HR managers recognized the most important areas of service delivery and strive to be more effective in these areas. Interestingly the correlation between mean importance and effectiveness ratings was 0.47 for the HR and 0.75 for the line managers. This indicates that the line managers strongly perceived that HR was more effective at delivering the important services and roles. A positive message here is that HR professionals could prioritize their work properly.

HR Contribution: Consistent with their rating on importance and effectiveness, the HR managers rated HR contributions as higher compared to the ratings given by the line managers (Figure 5). Overall, HR policies and procedures coming from HR department and their well coordination emerged as the major HR contributions. But value-added contribution to the firm's bottom line, and building and maintaining the firm's core competencies were the least HR contributions. It is significant to note that, in relative terms, the HR and the line managers' perceptions of HR's contributions seem to be converging with their ratings on the top and least contributions.

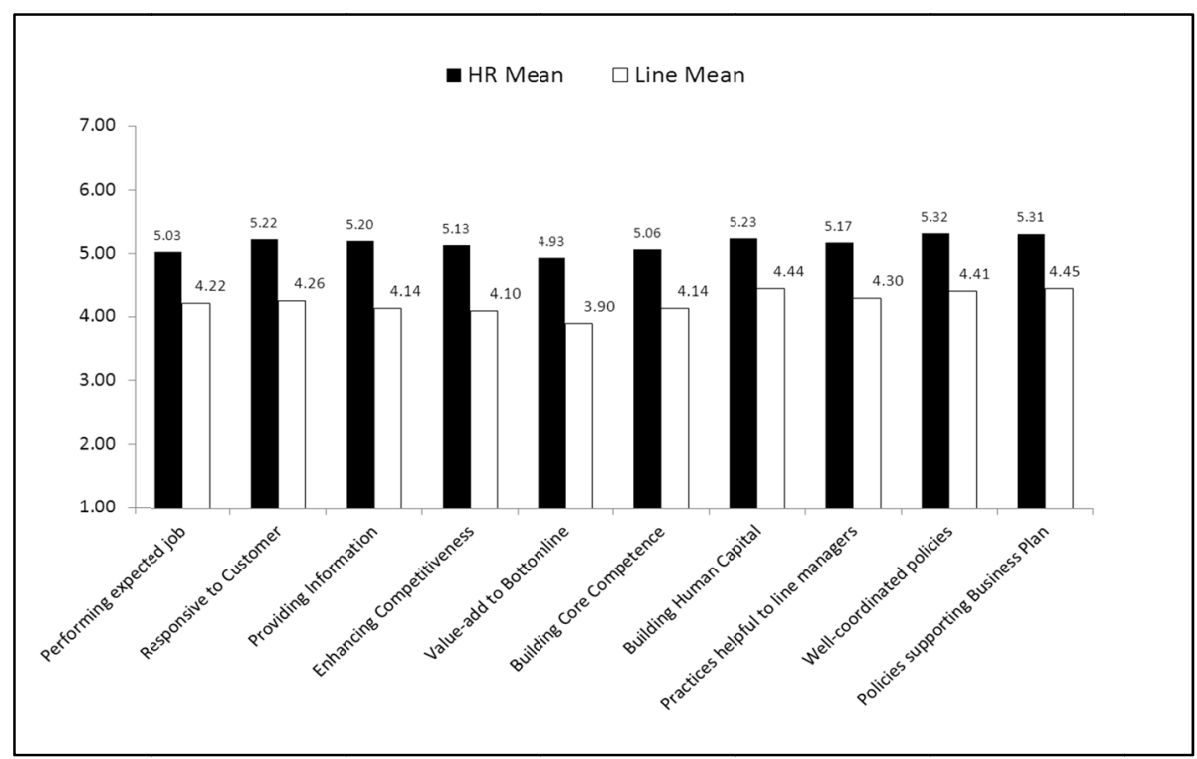

Figure 5. HR contributions

Nature of Business-Wise: An attempt was made to find out the differences of perceptions of the respondents on HR based on the nature of business of their respective organizations. Mean ratings showed a trend, where the 
line managers from manufacturing sector gave higher importance ratings for HR service delivery areas as well as HR roles, while the line managers from the service sector gave the lowest ratings among the three groups in most cases. Such a trend was also observed in case of HR contributions ratings but not in the case of effectiveness ratings. Box's Test for equality of covariance returned a significance level of 0.000 indicating that the covariance matrices amongst the importance, effectiveness and contribution variables were not the same across the three sectors. A Cronbach's Alpha of greater than 0.97 for all three sectors indicated excellent internal consistency. Pillai's Trace and Wilks' Lambda both returned a partial Eta Squared of 0.218 at a significance level of 0.000 indicating that about $22 \%$ of the variability in perceptions of importance, effectiveness and contribution of HR are accounted by the sector to which the organization belongs. ANOVA showed that a significant difference existed between importance ratings of the three sectors in case of some HR service areas, including labor relations, training, benefits cost control and engagement. When it came to effectiveness ratings, the picture was different than the importance ratings as significant differences were found in a few HR service areas including compensation, labor relations and controlling benefits cost. In case of HR contribution, ANOVA indicated significant difference in only one area of contribution, namely developing well-coordinated HR policies and procedures. Overall, it was found that the IT/ITES sector received relatively higher score in HR's importance, effectiveness and HR contributions. This was followed by the manufacturing sector. It is disheartening to note that in all three aspects, namely, HR's importance, effectiveness and HR contributions, service sector received the third position.

Organizational Size-Wise: There is an attempt made to find out the differences of perceptions of the respondents on HR based on their organizational size. Mean ratings showed a trend of the respondents in large organizations (5000-10000) giving higher importance and effectiveness ratings for HR service delivery areas and HR roles and higher rating for HR contributions. Box's Test for equality of Covariance returned a significance level of 0.000 indicating that the covariance matrices amongst the importance, effectiveness and contribution variables were not the same across the four categories of organizations according to their headcount. A Cronbach's Alpha of greater than 0.96 for all four categories indicated excellent internal consistency. Pillai's Trace and Wilks' Lambda returned a partial Eta Squared of 0.206 and 0.209 respectively at a significance level of 0.000 indicating that about $21 \%$ of the variability in perceptions of importance, effectiveness and HR contributions was accounted by the size of the organizations.

ANOVA showed that a significant difference existed between importance ratings of half the HR areas and roles, including the items such as providing performance based incentives, initiatives to contribute to business goals and the role of human capital builder and functional expert. When it came to effectiveness ratings, significant differences were indicated except for the areas of providing proactive labor relations support and compliance with legal regulations. With regard to HR contribution also, ANOVA indicated significant differences for more than half the variables including the contribution of having provided information related to HR issues and framed effective policies and procedures. Tukey and LSD showed that managers from small organizations (with less than 500 employees) gave lower importance to performance-based incentives than did managers from larger organizations. A similar theme was also observed on the importance ratings given to design of performance management programs, communication, and staffing.

Most of the differences between effectiveness ratings were observed with small organizations (less than 500 employees) on one side, and larger organizations (5000-10000) on the other, with HR being perceived as less effective in small organizations. Considering HR contributions, Tukey and LSD showed that a significant difference between organizations with 5000-10000 employees and those with above 10000 employees, where contributions seemed to peak in the first category and then decline as headcount increased over the 10000 employee level.

Geographical Orientation-Wise: Mean ratings showed a trend of managers from Indian multinational companies giving higher importance and effectiveness ratings for HR service delivery areas, HR roles, and contributions than their counterparts. Box's Test for equality of covariances returned a significant level of 0.000 indicating that the covariance matrices amongst the importance, effectiveness and contribution variables were not same across the three categories of organisations. A Cronbach's Alpha of greater than 0.96 for all three categories indicated excellent internal consistency. Pillai's Trace and Wilks' Lambda returned a partial Eta Squared of 0.195 and 0.209 respectively at a significance level of 0.000 indicating that about $20 \%$ of the variability in perceptions of importance, effectiveness and contribution of HR were accounted by the organizations' geographical orientation. ANOVA showed that a significant difference existed between HR's importance and HR roles ratings of the three groups in all HR service areas excepting labor relations support and the functional expert role. When it came to effectiveness ratings, the picture was different. Significant differences were found in a few areas including 
compensation, performance-based incentives and tracking measures to identify problems. As far as HR contributions are concerned, ANOVA indicated significant differences based on geographical orientation.

Tukey and LSD showed that, in case of importance ratings, it was the local Indian companies with their lower ratings which were responsible for so many significant differences reported by ANOVA. The respondents of Indian local companies gave lower importance ratings than their counterparts with respect to all HR areas and roles flagged by ANOVA. In some aspects, such as providing performance management programs and developing HR initiatives to respond to potential problems, the respondents of Indian MNCs gave significantly higher importance ratings than did managers in Foreign MNCs. A similar trend was observed in case of effectiveness ratings also with managers in local Indian companies giving significantly lower effectiveness ratings than their counterparts. In case of contribution, a similar theme was observed with the lower ratings given by managers from local Indian companies making the bulk of difference reported by ANOVA. Overall it was observed that Indian companies put less emphasis on HR and lagged on effectiveness parameters, while their local Indian MNC counterparts were at par or even better at making HR more effective than Foreign MNCs.

CEO Interface with HR: The respondents were asked to rate the involvement of CEO in HR management of their respective organizations. The organizations from where the respondents reported that the CEO actively involved with HR and extended regular support, showed a higher perception of HR's importance, effectiveness and contribution. At the same time, in organizations, where HR and CEO interface was occasional, based on the pressing need, lower perceptions of HR's importance, effectiveness and contribution were identified.

Line Managers' Involvement in HR Programs: The respondents were asked to rate the involvement of line managers ranging from 'no involvement' to 'significant involvement' in various HR programs. Interestingly, it was found that the respondents from the organizations where line management's involvement in HR programs was 'nil', showed higher perception of importance, effectiveness and contribution of HR. The respondents from the organizations where line management's involvement in HR programs was 'significant' showed lower perception of importance, effectiveness and contribution of HR.

\section{Conclusion}

This research examined the importance, effectiveness and contribution of HR from the viewpoint of line and HR professionals. The results show that when compared to line professionals, HR professionals perceive higher importance, effectiveness and contribution of HR. This is consistent with the finding of the earlier study conducted in USA by Wright et al. (2001). With regard to importance rating, this study differs with the finding of study conducted in China by Mitsuhashi et al. (2000), in which there are no significant differences between line and HR managers. However, with respect to effectiveness of HR performance, the findings of the present study and Chinese study are consistent.

The study further finds that line and HR professionals recognize the importance of HR and its roles for the firm's competitive advantage. Maintaining an equitable compensation system and performance-based incentives are the top two HR service delivery areas that contribute to gaining competitive advantage. When it comes to HR roles, human capital builder role contributes significantly.

Interestingly, the study indicates that the effectiveness of HR in the most important areas and roles was higher, while in least important areas it was lower. It seems the HR managers recognize the most important areas of service delivery and strive to be more effective in these areas. However, there are a few HR service delivery areas, such as developing initiatives to help build employee commitment, in which there is a significant gap between importance rating and effectiveness ratings.

As far as HR contributions are concerned, the study indicates that HR policies and procedures created by HR department and their well coordination are the major contributions of HR. They help front line managers in their day-to-day activities relating to their employees. However value-added contribution to the firm's bottom line, and building and maintaining the firm's core competencies are the areas of improvement. The good news is that line managers recognize the importance, effectiveness and contributions of HR. It is up to HR now to make the HR function more effective and thereby contribute to the firm's bottom line.

The study further identifies that importance of HR, its roles, its effectiveness and contributions are better recognized in IT/ITES sector than manufacturing and service sectors. Organizational size-wise, the study shows that HR is better recognized in large organizations than the small ones. Geographical orientation-wise, it is interesting to observe that managers of Indian multinational companies recognize greater importance of HR, its effectiveness and contribution, than foreign multinational and local Indian companies.

Another observation of the study is that, the higher the interface of CEOs with HR, higher is the recognition of 
HR's importance, and its effectiveness. However, with respect to line managers' involvement in HR, the study interestingly finds that the higher the involvement of line managers in HR, the lower the HR's importance and its effectiveness. It seems that though line managers are involved significantly in HR activities, their operational work pressures, lack of time, interest and competencies would have probably contributed to this perception. When HR is carried out by HR professionals who have the required qualifications, training and experience in the HR field, the importance, effectiveness and contribution of HR is better recognized.

\section{Limitations and Further Research}

This is the first study of its kind in India to assess HR importance, effectiveness and contributions using this set of variables. Though the study provides meaningful insights into the perceptions of line and HR professionals, there are certain limitations to this study. One is, that the source of information is self-reports of HR and line professionals. The distribution of the sample of organizations in terms of nature of business, geographical orientation, and organizational size is not even. This study finds that the higher the involvement of line managers in HR, the lower the HR's importance and its effectiveness. In the context of discussion on devolving HR activities for line managers, this may be an area of further research.

\section{References}

Becker, B. E., Huselid, M. A., \& Ulrich, D. (2001). The HR scorecard. Boston: Harvard Business School Press.

Cascio, W. F., \& Boudreau, J. (2008). Investing in people. New Jersey: Pearson Education .Inc.

Fitz-Enz, J. (2000a). The ROI of human capital. New York: AMACOM.

Fitz-Enz, J. (2010b). The new HR analytics: Predicting the economic value of your company's human capital investments. New York: AMACOM.

Flamholtz, E. (1985). Human resource accounting. San Francisco: Jossey-Bass.

Kaplan, R., \& Norton, D. (1996). Balanced scorecard. Boston: Harvard Business School Press.

Mitsuhashi, H., Park, H. J., Wright, P.M., \& Chua, R. S. (2000). Line and HR executives' perceptions of HR effectiveness in the firms in the People's Republic of China. International Journal of Human Resource management, 11(2), 197-216.

Phillips, J. J. (1999). Accountability in human resource management. Woburn: Butterworth-Heinemann.

Tsui, A. S. (1987). Defining the activities and effectiveness of human resource department: A multiple constituency approach. Human Resource Management, 1(26), 35-69.

Ulrich, D. (1997). Measuring Human Resources: An overview of practice and a prescription for results. Human Resource Management, 36(3), 303-320.

Ulrich, D., \& Brockbank, W. (2005). The human value proposition. Boston: Harvard Business School Press.

Wright, P. M., McMahan, G. C., Snell, A. S., \& Gerhart, B. (2001). Comparing line and HR executives' perceptions of HR effectiveness: Services, roles, and contributions. Human Resource Management, 40(2), $111-123$

Yeung, A. K., \& Berman, R (1997). Adding value through human Resources: Reorienting human resources measurement to drive business performance. Human Resource Management, 3(36), 321-33.

\section{Appendix A}

Variables of HR Importance and Effectiveness (Wright et al., 2001)

1. Maintaining an equitable compensation system that controls costs while ensuring that top performers are retained.

2. Maintaining performance-based incentives to motivate individuals to focus on achieving strategic goals.

3. Providing labor relations support to business partners and front-line managers.

4. Providing training and development programs to enable front-line managers to maximize their performance potential.

5. Providing performance improvement programs to develop and motivate to business partners and front-line managers. 
6. Communicating and marketing key business and human resource initiatives to business partners and front-line managers.

7. Maintaining effective staffing systems and succession plans to ensure a steady supply of talent.

8. Controlling employee benefit costs.

9. Developing HR initiatives that contribute to business goals.

10. Tracking trends (e.g., productivity, absenteeism, and turnover) to identify potential problems.

11. Developing HR initiatives to respond to potential problems.

12. Developing initiatives that build employee commitment.

13. Maintaining user friendly benefit administration system.

14. Providing support to ensure legal compliance.

15. Developing initiatives to exploit the value of diverse workforce.

\section{Appendix B}

Variables of HR contributions (Wright et al., 2001)

1. The HR department is performing its job the way I would like it to be performed.

2. The HR department is very response to meeting customer (line managers and employees) needs.

3. The HRD department provides me with useful and timely information regarding HR issues.

4. The HR department helps to enhance the firm's competitive position.

5. The HR department provides value-added contribution to the firm's bottom-line.

6. The HR department contributes to building and/or maintaining the firm's core competence.

7. The HR department contributes to building the firm's human capital as a source of competitive advantage.

8. The policies, procedures and practices coming from HR department help line managers and employees in their jobs.

9. The HR department has developed a well-coordinated set of policies, procedures and practices.

10. The HR policies, procedures and practices help support the firm's business plan.

\section{Copyrights}

Copyright for this article is retained by the author(s), with first publication rights granted to the journal.

This is an open-access article distributed under the terms and conditions of the Creative Commons Attribution license (http://creativecommons.org/licenses/by/3.0/). 